\title{
Entrevista com Víctor Bretón
}

\author{
Interview with Víctor Bretón
}

\section{Víctor Bretón Solo de Zaldívar}

É catedrático de Antropologia Social na Universidade de Lleida (Catalunha, Espanha) e professor emérito honorário da Faculdade Latino-Americana de Ciências Sociais (Flacso) - sede Equador. Especialista em teorias do desenvolvimento, economias camponesas e movimentos étnicos na América Latina, realizou investigações históricas e etnográficas na Espanha, no México e no Equador, destacando seus trabalhos sobre os movimentos indígenas na região andina em perspectiva histórica e comparada.

E-mail: breton@hahs.udl.cat;

\section{Tradução}

\section{Patrícia da Veiga Borges}

Doutora em Comunicação pela Escola de Comunicação da UFRJ.

Nesta entrevista exclusiva realizada para o dossiê "Novas Faces do Poder: líderes, política, estética, mídia”, a editora Beatriz Jaguaribe entrevistou o antropólogo Víctor Bretón. 0 pesquisador fez um balanço sobre as agendas políticas que marcam o debate contemporâneo e o legado dos acontecimentos politicos da década de 1960. Outras questões abordadas são as novas identidades indígenas e o fazer etnográfico em cenários de globalização cultural. 
Revista Eco-Pós: As novas faces do poder da ultradireita manifestam, em comum, uma retórica populista? Os ideais da ultradireita empoderada são reações às propostas de 1968? São uma reação às políticas identitárias atuais? São fruto de temores econômicos das classes médias debilitadas?

Víctor Bretón: É um fenômeno inquietante, sem dúvida, que exige uma reflexão muito séria e uma análise desapaixonada do conjunto de circunstâncias que facilitaram sua eclosão e sua cristalização - no Brasil, nos Estados Unidos e, de maneira distinta e com intensidades variáveis, em diferentes países europeus - em formas particulares de ocupação e exercício do poder. Trata-se de governos empoderados à base do voto democraticamente exercido pela cidadania, em primeiro lugar. Governos que demonstram, por outro lado, um desprezo atávico pelas instituições, pelo rigor ou pelos compromissos prévios contraídos por governos anteriores, muito embora o maior ou o menor grau de força institucional de cada país determine a capacidade de erosão sistêmica exercida pelo Executivo. Costumam se apropriar, em nome da democracia, da representatividade das "pessoas comuns", aquelas desdenhadas pelas elites políticas que, segundo a própria narrativa da ultradireita, corromperam o sentido democrático da política ao pensar unicamente na reprodução de seus pretensos privilégios. É muito difícil generalizar sobre realidades concretas tão diferentes, mas acredito que mutatis mutandis todas essas expressões políticas compartilham tais características. Nesse sentido, e particularmente pela encenação histriônica e sem complexos da ação performática do poder, sim, me parece que se pode qualificá-las como populistas. De modo geral, está claro que essa categoria não está mais associada, como foi teorizado na década de 1960, a um determinado ponto da história econômica e social dos países "em desenvolvimento" (Germani) e a uma agenda inclusiva - e com reforços redistributivos, acrescento - de setores subalternos tradicionalmente excluídos e não envolvidos, nesse sentido, nas agendas políticas anteriores. No momento, estamos testemunhando o arranjo de políticos que, em vez de portadores de um horizonte ideológico nítido ou de um roteiro econômico coerente, têm uma noção autoritária, nepotista e tremendamente heterogênea da gestão governamental. Uma gestão, do 
contrário, muito aparada por crematísticos interesses pessoais, familiares ou de uma minoria experiente de empresários ou especuladores com poucos escrúpulos e praticamente nenhuma visão das perdas sistêmicas - vistas tanto da perspectiva macro como da micro - que essa tão particular maneira de entender a política, sem dúvida, se entranhará em curto, médio e longo prazo. A ascensão e a proliferação desses fenômenos de ultradireita têm a ver, é claro, com uma reação visceral contra os grandes avanços, em termos de democratização de numerosos âmbitos do cotidiano, derivados da marca do espírito de 68 e, mais recentemente, do que significaram as políticas identitárias das últimas décadas, e me parece que este ponto merece uma reflexão à parte. A consolidação da globalização neoliberal, da década de 1980 em diante, trouxe consigo, em boa parte como resposta às suas tendências homogeneizantes, uma onda completa de redefinições de subjetividades que se tornaram nichos de múltiplas identidades referenciais (em termos de etnia, é claro, mas também de gênero, de orientação sexual, de sensibilidades em relação a diferentes itens - direitos dos animais, defesa do meio ambiente e muitos outros) que contribuíram para articular uma sociedade civil organizada, mas, ao mesmo tempo, muito fragmentada, minando paralelamente as antigas atribuições classistas, base do sindicalismo e da militância clássica de esquerda. A isso favoreceu demasiadamente a implosão dos regimes do socialismo real e a publicização, por meio da mídia, do significado do fim da Guerra Fria como o advento de uma nova era que, para alguns intelectuais orgânicos da pós-modernidade, foi, inclusive, caracterizado pela opulenta expressão "fim da História" (Fukuyama). Tudo isso, que teve um efeito devastador no que corresponde à possibilidade de gerar respostas coletivas contundentes - na forma, por que não, de um novo pacto social - frente aos desafios impostos pelo capitalismo neoliberal (tais como o incremento da inequidade ou o desmantelamento progressivo e inevitável das instâncias estatais e supranacionais de proteção social), teve a consequência, apesar disso, de visibilizar e democratizar espaços até então obscurecidos, sancionando por meio das políticas identitárias determinados direitos (basicamente os vinculados à diferença, por distintos contornos de autodeclaração), inclusive por meio de discutidas e discutíveis práticas de discriminação positiva. Pois bem, todos esses direitos conquistados, que não são 
poucos nem menores, correm hoje risco evidente nas mãos do rearranjo dos posicionamentos mais escabrosos, intolerantes e retrógrados imagináveis. E o mais grave é que esse rearranjo - na Polônia, na Hungria, no Brasil, nos Estados Unidos, na Itália - conta com o apoio eleitoral de amplos setores da classe média em processo de empobrecimento e de setores populares em outros tempos tributários do voto em conformações políticas com discurso de esquerda.

Essa situação é muito evidente na Europa e na América do Norte, onde a volatização do Estado de Bem-Estar Social (Europa Ocidental); a frustração gerada pela transição do socialismo real a uma União Europeia - outrora sonhada como paradigma do Wellfare State - depreciada à mera condição de grande mercado com escassa capacidade de intervenção em matérias de políticas sociais (Hungria, Polônia); ou as enormes incertezas que os fluxos migratórios, a deslocalização industrial e a erosão geral da renda entre a antiga classe trabalhadora desproletarizada e segmentos da classe média (Estados Unidos, Europa), se tornaram caldo de cultura dessas novas formas de autoritarismo com roupagem democrática que estamos comentando. Em casos como o do Brasil, além disso, creio que a esquerda deveria fazer uma leitura crítica do ocorrido durante os anos de bonança econômica geridos por ela. Pode ser, por exemplo, que mais que livrar várias dezenas de milhões de pessoas da pobreza, as tenha introduzido na cultura e na lógica do consumo - o que não é o mesmo, absolutamente. Talvez a rede tradicional de votos da esquerda - o volátil, heterogêneo e muitas vezes incompreendido mundo "dos pobres" - esteja mais cruzado pelo desejo consumista do que por uma eventual consciência de classe que não existe e nem se espera que exista. Se a isso acrescentarmos o cenário da violência indiscriminada atravessada pelo narcotráfico e pelas máfias de todo tipo que permeiam esses mundos, a possibilidade de um transbordamento notório de votos até opções políticas como a que atualmente preside o país está servida, como aconteceu nas últimas eleições.

O medo e a incerteza que geram o atual cenário em praticamente todas as partes do mundo são solo fértil para o autoritarismo populista. Já advertiu Karl Polanyi 
em A Grande Transformação (The Great Transformation, 1944), a respeito do nascimento do fascismo e da tragédia da Guerra Mundial, de que modo isso aconteceu como consequência da subordinação do político ao econômico, situação que detonou as possibilidades de convivialidade que, por acaso, o velho liberalismo continha. Oitenta anos depois, em meio a uma fase em que a economia financeira especulativa tomou as rédeas do capitalismo global, afastando-se (e prescindindo) dos setores geradores de riqueza (no sentido convencional e neoclássico do termo), e em que a capacidade da política de implementar medidas corretivas ou limitantes dos efeitos sociais desses insensíveis processos de acumulação por expropriação (Harvey) é frustrante (por ser insignificante), as novas faces da ultradireita se proliferam e impõem uma agenda econômica, política e social despropositada, injusta, autoritária e explosiva do ponto de vista da convivência e da mesma sustentabilidade do sistema que os ampara.

Revista Eco-Pós: Atualmente, há um intenso debate no Brasil sobre as identidades indígenas e suas configurações. Novos líderes indígenas emergem não somente na Amazônia, mas também no contexto urbano. Dada sua longa história como antropólogo nas comunidades indígenas rurais dos Andes do Equador e seu conhecimento comparativo das construções políticas indígenas no Peru e na Bolívia, poderia comentar sobre estas diversas formas de "invenções" de identidades indígenas? Como se constroem essas identidades na confluência das formas globais, nacionais e políticas de fundações e ONGs?

Víctor Bretón: Meu trabalho etnográfico de mais de duas décadas nos Andes me permitiu constatar, para países como Equador e Bolívia, a convergência de alguns processos que se deram entre os anos 80 do século passado e a chegada dos "regimes progressistas" na primeira década do XXI: o auge do neoliberalismo como dogma regente das políticas econômicas (e sociais); a emergência de plataformas indigenistas e partidos políticos fortemente etnicizados, em parte como reação ao custo social da agenda neoliberal; e o giro étnico nas prioridades do aparato de 
desenvolvimento, bem incorporado ao trabalho da maior parte da cooperação internacional.

O apogeu do neoliberalismo, de fato, coincidiu com a irrupção das grandes organizações indígenas. No caso andino, a construção dessas plataformas se sobrepôs a processos anteriores de luta pela terra e a reformas agrárias que, com nuances, não resolveram a espinhosa "questão agrária". Na Amazônia, foram as ondas colonizadoras - produto também das legislações reformistas - que, junto às consecutivas iniciativas extrativistas, constituíram o húmus das demandas posteriores em favor do reconhecimento do direito ao território por parte de povos e nacionalidades indígenas. Em qualquer caso, foi nos anos 80 que se consumou a transição de discursos fundamentais classistas, próprios das décadas anteriores, a outros de carácter identitário que, por não deixar de lado as demandas vinculadas à sua condição de grupos subalternos, mostraram grande capacidade de estabelecer pontes com setores não indígenas também golpeados pelas políticas de ajuste, garantindo assim o êxito mobilizador dos anos 90 (Equador) e os primeiros anos deste novo século (Bolívia) capitaneado pelos movimentos indígenas. Este é um fenômeno que vai mais além da região andina, desde já, pois projeta reverberações com processos paralelos como, entre outros, o dos neozapatistas chiapanecos ou o novidadeiro movimento pan-maia na Guatemala pós-conflito bélico.

Tudo isso convergiu com o boom da "cooperação descentralizada" por meio da presença massiva de Organizações Não Governamentais (ONG). É bem conhecido, neste sentido, o chamado que o próprio Banco Mundial realizou, em 1982, às ONGs para que se envolvessem ativamente nas políticas de desenvolvimento na América Latina, ao mesmo tempo em que apostava em uma agenda desrreguladora e privatizadora. $\mathrm{O}$ "modelo $\mathrm{ONG",} \mathrm{pois,} \mathrm{se} \mathrm{constituiu} \mathrm{como} \mathrm{a} \mathrm{contrapartida} \mathrm{neoliberal} \mathrm{no}$ que se refere às políticas sociais, apesar da doutrina externalizadora do Consenso de Washington. Nesse contexto complexo, as plataformas étnico-identitárias se tornaram - perante a crise da esquerda depois da queda do muro de Berlim - as principais instâncias de resistência anti-ajuste, tanto no Equador como na Bolívia. 
Instancias que, certamente, se fortaleceram como agentes políticos nessa conjuntura. Daí a ênfase do aparato de desenvolvimento (com as ONGs na centralidade) em priorizar suas atuações sobre cenários predominantemente indígenas. Visto em perspectiva, essa inclinação da cooperação internacional até o étnico teve resultados inócuos sob o ponto de vista do combate à pobreza (basta uma verificação breve dos indicadores disponíveis sobre os povos indígenas para comprovar), mas foi muito relevante em termos de politização dessas plataformas organizativas (parte da antiga intelectualidade de esquerda se refugiou nas ONGs depois do colapso de seus partidos e sindicatos tradicionais). Contudo, e aí está o lado ambivalente e paradoxal do assunto, em casos como o do Equador finissecular ou da Bolívia do "multiculturalismo neoliberal", isso redundou - via essencialização de seus discursos e/ou cooptação de parte de seus dirigentes - em seu paulatino enquadramento dentro do campo de jogo do projetismo. Neste sentido, parafraseando Ferguson, se poderia aplicar a esse modelo de intervenção em nome do desenvolvimento a metáfora da "Anti-Politics Machine".

A particularidade do Peru em todo esse elenco de relações foi destacada por numerosos analistas: diferentemente do Equador e da Bolívia, não foi nos Andes peruanos senão na Amazônia onde emergiram as organizações indígenas mais fortes, permanecendo a serra em um estado "anômalo" em relação aos países vizinhos. A reforma agrária peruana foi das mais importantes da América Latina dos anos 60 e 70 em volume de superfície redistribuída, ao mesmo tempo em que marcou o fim brusco e sem possibilidade de voltar atrás no regime de fazendas e plantações - o célebre gamonalismo denunciado, por sua vez, por Mariátegui. Mas, convém não esquecer que os limites da reforma agrária, em relação às tremendas expectativas por ela geradas, estão na base do início da violência política à qual se viu submetido o país durante mais de 20 anos. Na barbárie desatada na guerra do Sendeiro Luminoso contra o Estado e na repressão muitas vezes indiscriminada das forças armadas encontra-se, de fato, uma das chaves da reiterada excepcionalidade peruana enquanto elemento debilitador das bases de possíveis mobilizações indígenas na serra. Somam-se a isso elementos como o volume e a intensidade dos processos 
migratórios internos; a conformação contemporânea das elites intelectuais étnicas comparáveis às equatorianas e bolivianas; a apropriação - por sua vez, causa e consequência do anterior - de numerosos elementos simbólicos das culturas indígenas por parte de setores dominantes branco-mestiços (aspecto notável em contextos como Cuzco ou Ayacucho, para citar alguns); ou o fato de ter a capital na costa, com todo o peso de Lima em um processo de construção nacional que, arrastando uma série de preconceitos anti-andinos desde o tempo colonial, contrapôs a "modernidade" encarnada na cultura hispânica e a mestiçagem ao "tradicionalismo" de uma visão arcaizante do "andino".

Mas, para além da casuística que, tendo como base a própria história, explica a etnização do protesto social em uma conjuntura específica de países como Equador e Bolívia, é preciso entender como essa se consolidou num cenário global em que o identitário se tornou um fenômeno coberto por concessões heterogêneas locais cruzadas - na América Latina, mas também na Europa, África e Ásia - por reinvenção permanente do "próprio", entendido como uma forma de reivindicar o autóctone e, com isso, direitos ligados ao reconhecimento e ao acesso a recursos, materiais e simbólicos. 0 que quero dizer é que, neste marco de realidades líquidas (Bauman) e liquefação das grandes utopias da modernidade, com sua correspondente carga de incertezas e desconcertos, a apelação à identidade - sempre revestida de doses variáveis de ancestralidade e autenticidade, claro - ocupou um lugar central na cena pública. E aí [é preciso destacar] o papel dos meios de comunicação de massa e da circulação em escala planetária de todos os produtos e artefatos da indústria cultural, que retroalimentaram e impulsionaram esses processos de um modo formidável.

A fulgurante carreira política (e midiática) de uma personagem como Evo Morales, por exemplo, não pode ser entendida sem se ter em conta as consequências em longo prazo da reforma agrária boliviana dos anos 50, sem dúvidas, porém, tampouco sem considerar a projeção de sua figura pelos meios e a reverberação de múltiplas imagens projetadas e em circulação simultânea de tantas outras realida- 
des "étnicas" que são consumidas nos novos cenários de etnicidades ressignificadas e ubiquamente restauradas. A decomposição das antigas formas de gestão comunitária de recursos, a reconversão das "comunidades" em redes sociais que atravessam os espaços rurais e urbanos, desfocando seus limites, e que rompem também as barreiras regionais e internacionais, são algumas das características do entorno econômico, social e cultural no qual essas novas identidades são sustentadas. Aí se encaixa o processo - contestável no Brasil, no México e no Peru - de reivindicação do "indígena" em contextos urbanos ou periurbanos, algo simplesmente inconcebível poucas décadas atrás.

Revista Eco-Pós: Em sua trajetória como antropólogo, como interpreta atualmente os estudos etnográficos? A antropologia surgiu em um contexto europeu de expansão dos domínios coloniais, como entender o fazer etnográfico atualmente? Quais são os pactos entre o antropólogo e as comunidades estudadas?

Víctor Bretón: Certamente, a Antropologia como disciplina científica é, como muitas outras, filha do colonialismo europeu e seus adjacentes, como o neocolonialismo norte-americano. Isso nos levaria a uma reflexão sobre as implicações e as imbricações do conhecimento científico - entendido como uma maneira particular de apreender a realidade caracterizada pela aplicação do método hipotético-dedutivo com o objetivo de facilitar a intervenção sobre essa realidade - e o poder. No caso das disciplinas sociais, e em particular no caso da Antropologia, isso se traduziu na ilusão de matriz positivista de obter pautas que permitisse conceber políticas com a finalidade de submeter, disciplinar e aculturar - em nome, depende do momento, do progresso, da civilização ou do desenvolvimento - a todas aquelas sociedadesoutras presas na retícula do domínio colonial e pós-colonial. Nos levaria também, acertadamente, a retomar noções como a colonialidade do saber (Quijano) como ferramenta a favor da consolidação de formas hegemônicas de exercício de poder, no sentido gramsciano do termo, em que subalternos (na qualidade de "primitivos", "tradicionais" ou "subdesenvolvidos") chegam a naturalizar sua situação de- 
pendente e a assumir as bondades da episteme dominante como redentora de suas carências.

Nessa corrida pela construção de um conhecimento minucioso das alteridades sociais e culturais, o trabalho etnográfico constituiu uma ferramenta particularmente estimulante. A Antropologia se especializou, de fato, na aproximação ao mundo dos "outros" a partir de dentro e a partir de baixo, aplicando as mais novidadeiras técnicas do trabalho etnográfico. E dessa maneira, como sem querer, foi consolidando uma imagem naife de uma "sociedade primitiva" quasi originária que talvez nunca existiu, ou ao menos que deixou de existir, como nos recordava Eric Wolf, com a expansão europeia da modernidade. Adam Kuper destacou há 30 anos o modo com que a Antropologia anglo-saxônica evolucionista do século XIX construiu esse tema, em boa parte revestindo de positivismo o antigo mito ilustrado dos "povos sem História". E mais adiante, a revolução funcionalista de Malinowski e RadcliffeBrown, graças a sua ênfase no trabalho de campo e na obtenção de evidências empíricas sobre o terreno, converteu esse mito em uma hipótese científica supostamente verificada. Essa sociedade primitiva incontaminada que as páginas de $O s$ argonautas do Pacífico Ocidental resumem, por exemplo, contrasta extremamente com o diário de campo em que o mesmo autor, Malinowski, descreve com toda naturalidade a presença de personagens seletivamente extirpadas da monografia que evidenciam a contemporaneidade dessas não tão priscas comunidades nativas tão atravessadas por administradores coloniais, telegrafistas, pastores anglicanos e colonos experientes em busca de retorno econômico no crepúsculo do último grande império europeu. 0 que quero dizer é que essa comunidade fechada, autárquica e isolada descrita em uma infinidade de etnografias redigidas, e o dado é relevante, a partir de uma grande diversidade paradigmática -funcionalismo, estruturalismo, marxismo, neoevolucionismo, ecologia cultural - diz respeito mais a um preconceito (incapacidade epistemológica, talvez?) do que a uma realidade verificável. Por sorte, contamos também com o contraponto de numerosos trabalhos que dão relevo à porosidade das culturas, sua natureza relacional e a importância 
da hibridação (Garcia-Canclini) em praticamente todos os processos etnográficos de etnogênese ou ressignificação identitária.

No caso dos estudos andinos, durante muitas décadas a Antropologia e a Etnohistória se moveram em parâmetros similares aos antes descritos. Essa síndrome "malinowskiana" - me permita a expressão - se traduzia em uma sorte de busca por um "mundo perdido" que, por razões nunca explicadas, persistia nas comunidades indígenas e camponesas como se preservado em um frasco de formol. A mesma evolução do conhecimento e a teimosia da realidade, por sorte, foram botando as coisas em seus lugares e hoje existe um certo consenso ao redor do caráter versátil, contingente, adaptativo e aberto de todas as formas culturais num sentido amplo (incluindo as formas de organização, as estratégias de produçãoreprodução e os modos de autorrepresentação e construção de subjetividades). Acompanhamos, entretanto, uma tendência também importante de reedificação de novas imagens essencializadas, inclusive retoricamente associadas a projetos políticos supostamente transformadores e questionadores do status quo. Os intelectuais orgânicos dos regimes do chamado "socialismo do século XXI", por exemplo, em convivência (ao menos numa primeira etapa de seu desempenho no poder) com intelectuais e acadêmicos críticos aos paradigmas dominantes e sua carga etnocida, abraçaram de maneira acrítica noções que, como o Bem Viver, se pressupõem ancoradas a outras ontologias andino-amazônicas que permaneceram estranhamente incontaminadas durante os últimos quinhentos anos. Claro que as práticas extrativistas desses governos - e de novo o Equador de [Rafael] Correa e a Bolívia de Morales voltam a ser exemplos emblemáticos neste assunto - terminaram se afastando dessa rara aliança epistêmica, entretanto, continua muito viva a persistente obsessão em determinados nichos do ativismo altermundista por uma imagem adoçada que apresenta o mundo indígena como ontologicamente ecológico, resistente, equitativo e portador de valores genuínos moralmente superiores aos de um "Ocidente" (outro enigma, por certo) depravador, colonialista e etnocida por metonímia. 
Os grupos subalternos, e mais aqueles secularmente racializados como inferiores, podem ser "ecológicos" ou não (depende de como definiremos tão singular categoria e depende também do momento e da conjuntura); podem "resistir" à penetração das empresas extrativistas ou querer negociar com elas; podem encobrir, sob narrativas exemplares que circulam muito bem nos meios de comunicação, realidades internas de exploração nua e crua (com base na idade, no gênero ou na condição socioeconômica). 0 que quero dizer com tudo isso? Que, na minha opinião, a etnografia tem muito o que fazer neste complexo cenário. Em vários sentidos. Em primeiro lugar, se bem é certo que a Antropologia e as demais ciências sociais têm sido, são e serão instrumentos privilegiados pelo establishment para reproduzir inequidades (nisso se inclui a lista de antropólogos, sociólogos e economistas contratados pelo Banco Mundial para planejar modelos de intervenção eficientes e de baixo custo a serem publicizados e orientar as políticas de desenvolvimento de estados, ONGs e instituições financeiras multilaterais), também é verdade, creio, que a única maneira de contribuir para a construção, quiçá, de uma alternativa ao pensamento dominante passa, necessariamente, pela obtenção de conhecimento verdadeiro e objetivável, na medida do possível, dos processos sociais contemporâneos. Vamos mal quando uma determinada prática política pretende se legitimar a partir de visões adoçadas e distorcidas, por mais que sejam bem intencionadas, dessa realidade social. Em segundo lugar, e está relacionado a isso, o trabalho etnográfico honesto, sem preconceitos e rigoroso, pode contribuir para combater essa tendência mencionada ao essencialismo, um verdadeiro mal que atravessa todas nossas disciplinas e que constitui, no meu ponto de vista, um grande obstáculo ao esclarecimento das lógicas subjacentes - habitualmente não evidentes que permeiam a complexidade deste pluriverso em constante mutação em que vivemos.

Estas reflexões acerca dos usos e abusos dos olhares essencializados sobre os povos indígenas por parte de ativistas e militantes de esquerda não nos deve fazer perder de vista, contudo, que a ameaça sobre esses mesmos povos e a biodiversidade na qual eles ainda se assentam (estou pensando, basicamente, ainda que não 
somente, na rica casuística da bacia amazônica) representa a atual reorganização de facto do desenvolvimentismo mais simplório, arrogante e perigoso que parte tanto de governos nacional-populistas de direita pura e dura (Brasil) como de governos situados à esquerda do espectro político e com discursos indigenistas contraditórios e ambivalentes (Bolívia). Em um e outro caso encontramos, em relação à questão amazônica (e no caso boliviano, somente se referindo a ela), um mínimo denominador comum discursivo - outro tópico essencialista - que passa pela imagem de indígenas indolentes, pouco produtivos, comodamente arraigados à sua pobreza diante de um território vastíssimo e riquíssimo praticamente inexplorado, e a quem se há de reorientar rumo a atividades produtivas e cujo hinterland deve ser, em qualquer caso, posto a serviço do desenvolvimento e do bem estar do país em seu conjunto. Outra evidência, em suma, da indispensabilidade de uma etnografia rigorosa e capaz de oferecer contrapontos discursivos a todas essas visões distorcidas é que, de fato, desprezam a tentativa de entender as práticas, os sentimentos, as subjetividades e os anseios cotidianos dessas alteridades que são vistas permanentemente por meio dos espelhos deformados do bem ou do mal, dependendo da orientação político-ideológica do observador de plantão.

A respeito do espinhoso tema da relação do investigador com a comunidade etnografada, penso que sempre há um pacto tácito funcionando; e atenção porque falo de "comunidade" e abro um parêntese em consonância com o que disse anteriormente, não pensando tanto em um lugar único e exclusivo como em uma rede mais o menos extensa de relações e conexões sociais. Minha experiência etnográfica me ensinou como o "terreno" do trabalho de campo se dilatou extraordinariamente: as comunidades indígenas que estou etnografando agora na província de Chimborazo, nos Andes centrais do Equador, têm seu epicentro - entendido, simplesmente, como um locus de referência identitário - nas terras altas chimboracenses, certamente, mas se constituem em redes com múltiplos terminais que vão desde o Queens, em Nueva York, até o mercado atacadista de São Roque, na cidade de Quito, passando por Guaiaquil e alguns dos grandes empórios agroexportadores da costa do Pacífico. E as pessoas pertencentes às comunidades, que não por residir nos Esta- 
dos Unidos ou na capital da República perdem tal condição, se comunicam por meio de Facebook, Whatsapp, Twitter ou Instagram, compartilham vídeos por essas plataformas, consomem todo tipo de artefatos culturais circulantes pelos mercados globais, reconstituem e ressignificam permanentemente sua identidade nesse magma aparentemente caótico resultante da convergência da globalização neoliberal com a revolução tecnológica em curso. Nesse marco, voltando à questão do pacto do etnógrafo, é evidente que nem todo mundo tem um código ético de retroalimentação, sendo por desgraça frequentes as práticas "extrativistas", no sentido de retirar informação in situ, em qualquer dos terminais da rede, e desaparecer depois para nunca mais. Me parece que o trabalho honesto passa por um certo compromisso de fazer chegar os resultados às pessoas e aos coletivos implicados, de lhes fazer participantes dos avanços da investigação, de socializar de maneira participativa tudo isso e de transmitir, assim, a imagem da utilidade do conhecimento em termos de informar as decisões, nesse caso, no âmbito das relações com autoridades, agências de fomento ou instituições religiosas, para mencionar alguns exemplos recorrentes no efervescente mundo andino. Também considerei sempre fundamental deixar claro que estamos em dívida para com as pessoas com as quais (e sobre as quais) trabalhamos porque, e isso sim é bem forte no fazer etnográfico, nada vulta a ser igual para o investigador em sua forma de ver as coisas depois da experiência prolongada de mergulhar entre as águas revoltas da vida alheia. 